\title{
DA COMPETÊNCIA DE ESTADOS E MUNICÍPIOS EM MATÉRIA DE SEGURANÇA SANITÁRIA. ASPECTOS TECNOLÓGICOS
}

\author{
STATE AND LOCAL COMPETENCY IN SANITARY SECURITY. \\ TECHNOLOGICAL ASPECTS
}

Antonio Joaquim Fernandes Neto ${ }^{(*)}$

\section{RESUMO}

A ANVISA (Agência Nacional de Vigilância Sanitária) foi criada pela Lei n. 9.782, de 26 de janeiro de 1999, com a finalidade de proteger a saúde por intermédio do controle sanitário. No entanto, surgiu de seu advento a confusão entre suas atribuições e a de outros órgãos virtualmente competentes. A questão que surge assim é relativa à competência e ao conjunto de funções da Agência.

A função da Vigilância Sanitária encerra a avaliação do processo tecnológico e a determinação de providências sobre ele. Neste campo, tanto Estados quanto Municípios são competentes, gerando o conflito em relação à matéria de segurança sanitária.

Não se separa qualidade do produto da sua forma de produção e, portanto, o zelo pela saúde deve estar harmonizado com a formulação constitucional desse direito: individual e coletivo, incluindo estes dois aspectos. Ademais, a ciência e a tecnologia devem estar a serviço dos direitos fundamentais, entre eles a saúde. Ao SUS (Sistema Único de Saúde) cabe o cuidado com os aspectos de produção e ao Ministério da Saúde, o incentivo à pesquisa e ao desenvolvimento de tecnologia, lembrando que existem diferentes perspectivas da tecnologia para os diversos órgãos que atuam sobre ela.

\section{Palavras-chave}

Competências, Tecnologia, Vigilância Sanitária.

\section{ABSTRACT}

ANVISA (National Agency of Sanitary Surveillance) was created by Law 9.782 , of 26 January 1999 , for the protection of health through sanitary con-

$\left(^{\star}\right)$ Procurador da Justiça no Ministério Público do Estado de Minas Gerais. 
trol. Its attributions compete with the regulatory power of other state sectors. The question lies in the normative power and the functions of the new agency.

It competes to the Sanitary Surveillance in state and local levels the evaluation and control of technological processes, but conflicts between these two levels occur. As the quality control of products is part of the production process, health care must follow the individual and collective aspects of the constitutional right to health. Science and technology must serve the fundamental rights, including the right to health. The SUS - Unified Health System - by law in charge of the sanitary control of production processes and the National Ministry of Health is in charge of the promotion of technological and scientific research and development, including the different technological aspects dealt by the different state sectors.

\section{Key words}

Fundamental Rights, Right to Health, Regulative Power, Technology, Sanitary Surveillance.

"A saúde é direito de todos e dever do Estado, garantido mediante políticas sociais e econômicas que visem à redução do risco de doença e de outros agravos e ao acesso igualitário às ações e serviços para sua promoção, proteção e recuperação."(1)

"A ação administrativa é confiada a uma série de agentes, dispostos em uma subordinação hierarquia, em harmonia com as divisões territoriais."(2)

"Competência é o conjunto de atribuições das pessoas jurídicas, órgãos e agentes, fixadas pelo direito positivo."(3)

\section{INTRODUÇÃO}

Os Estados e Municípios estão obrigados a "cuidar da saúde", competência comum também da União. Esta, na implementação de um novo modelo de gestão, acaba de criar a Agência Nacional de Vigilância Sanitária(4) - ANVS, órgão encarregado de coordenar o Sistema Nacional de Vigilância Sanitária, sob o comando do Sistema Único de Saúde - SUS.

(1) Constituição Federal, art. 196.

(2) URUGUAl, Paulino José Soares de Souza, Visconde de. Ensaio sobre o Direito Administrativo. Brasilia: Ministério da Justiça, 1997, p. 117

(3) DI PIETRO, Maria Sylvia Zanella. "Direito Administrativo". 11ª ed., São Paulo: Atlas, 1999, p. 188.

(4) A Agência Nacional de Vigilância Sanitária foi criada pela Lei n. 9.782, de 26 de janeiro de 1999 
Cuidados com a saúde abrangem várias atividades tendentes a eliminar, diminuir e prevenir riscos ao bem-estar da população, ou seja, incluemse oportunas e prontas intervenções nos problemas sanitários, quer decorrentes do meio ambiente, da produção e circulação de bens, quer da prestação de serviços, sempre no interesse da saúde pública. São todas, em resumo, ações de vigilância sanitária. ${ }^{(5)}$

Entre as mais importantes funções da vigilância sanitária está a avaliação dos processos tecnológicos empregados na produçāo de águas, alimentos e bebidas, bem como seus impactos na saúde e no meio ambiente. ${ }^{(6)}$ Os fornecedores de produtos e serviços estão obrigados a descrever seu sistema de controle de qualidade em documento escrito - as Boas Práticas de Fabricação - no qual são apontados os pontos críticos, para controle de situaçōes de risco.

Em Minas Gerais, um caso comprovado de intoxicaçăo provocada por refrigerante levou à interdição do prođuto, pela vigilância sanitária. Foi avaliado todo o processo tecnológico, constatando-se diversas falhas. Com o Compromisso de Ajustamento, a produção foi liberada.

$O$ ato, praticado no âmbito do SUS, deixou inconformado Luiz Ferreira Filho, Coordenador Substituto de Inspeção Vegetal do Ministério da Agricultura e do Abastecimento, que considera de sua responsabilidade todos os aspectos tecnológicos da fabricação de bebidas.

Entendo tratar-se de um equivoco essa disputa entre o Ministério da Agricultura e a ANVS. Foi mera tentativa de tirar do SUS sua competência legal para fiscalizar e garantir a identidade e a qualidade do produto sob o ponto de vista da proteção da saúde e da segurança individual e coletiva. Com a criação da agência executiva de vigilância sanitária, é natural a movimentação dos órgāos de fiscalização na realização das tarefas que the são próprias. ${ }^{(7)}$ A solução desse problema exige algumas reflexões sobre "tecno-

(5) "A expressão PRÁTICA SANITÁRIA constitui um bom exemplo daqueles nomes conhecidos $\theta$ aceitos por especialistas numa certa área do conhecimento, mas quase desconhecidos do público em geral. Entre os militantes no campo da saúde, prática sanitária é, reconhecidamente, a forma pela qual a sociedade estrutura e organiza as respostas aos problemas de saúde." SANTOS, Jair Licio Ferreira e WESTPHAL, Márcia Faria. "Práticas emergentes de um novo paradigma da saúde: o papel da universidade". In Estudos Avançados. São Paulo: Universidade de São Paulo, v. 35. 1999, p. 71

(6) "O principio da economicidade é o critério que condiciona as escolhas que o mercado ou o Estado, ao regular a atividade econômica, devem fazer constantemente, de tal sorte que o resultado final seja sempre mais vantajoso que os custos sociais envolvidos. Nessas escolhas estarão sempre presentes os critérios da quantidade e da qualidade, de cujo confronto resultará o ato a ser praticado. As ações econômicas não podem tender, em nivel social, somente à obtenção da maior quantidade possivel de bens, mas à melhor qualidade de vida." FONSECA, João Bosco Leopoldino da. "Direito Econômico". Rio de Janeiro: Forense, 1995, p. 33.

(7) "A adoção de determinada política econômica leva também a conflitos com o objetivo de outra, como, por exemplo, a adoção de uma política energética pode levar, e freqüentemente leva, a confrontos com as preocupações de uma política ambiental. Podem ocorrer também conflitos entre 
logia e direito". Estaria em vigor o art. $2^{\circ}$ da Lei n. 8.918 , de 14 de julho de $1994^{\left({ }^{(8)}\right.}$ ? Afirmativa a resposta, pergunta-se: qual o alcance da expressão "aspectos tecnológicos"?

A Lei n. 9.782, de 26 de janeiro de 1999, criou a Agência. E o fez com a finalidade institucional de promover a proteção à saúde da população por intermédio do controle sanitário, não só da produção e da comercialização de produtos e serviços submetidos à vigilância sanitária, como também do controle dos ambientes, dos processos, dos insumos, das tecnologias a eles relacionados, e ainda dos portos, aeroportos e fronteiras. (art. 6o $)^{(9)}$

"Decidida a garantir o direito à saúde para todos", conforme anota Sueli Dallari, a Constituição de 1988 disciplinou as atividades governamentais destinadas a cumprir o dever de "cuidar da saúde". Localizada entre as competências comuns à União, aos Estados, ao Distrito Federal e aos Municípios (art. 23, II), "cuidar da saúde" é tarefa "que a todos deve incumbir".

Também tem origem na Constituição Federal a concorrente compe. tência para legislar sobre a proteção e defesa da saúde, "reservando, assim, à União o estabelecimento das normas gerais, e deixando aos Estados e Municípios suplementá-las (art. 24, $\S \S 1^{\circ}$ e $2^{\circ} \mathrm{c} / \mathrm{c}$ art. 30, II)".(10)

Nas próximas linhas, vamos tratar da competência da Vigilância Sanitária, nos Estados e Municípios, em relação aos ambientes, processos, insumos e tecnologias a eles relacionados.

Em outras palavras, o estudo procura identificar o "conjunto de atribuições das pessoas jurídicas, órgãos e agentes, fixados pelo direito positivo"(11) em matéria de Vigilância Sanitária. Assim, se a competência da União limita-se ao estabelecimento de normas gerais, é preciso identificar quais são as obrigações dos Estados e dos Municípios. Depois, na legislação local, identificar como as funções de Vigilância Sanitária "são distribuídas en-

os objetivos imediatos de uma politica social e os de uma politica de competitividade industrial." FONSECA, João Bosco Leopoldino da. "Direito Econômico", cit., p. 202.

(8) Lei n. 8.918, de 14 de julho de 1994. Art. $2^{\circ} \mathrm{O}$ registro, a padronização, e, ainda, a inspeção e a fiscalizaçāo da produção e do comércio de bebidas em relação aos seus aspectos tecnológicos compete ao Ministério da Agricultura e do Abastecimento. Art. $3^{2} \mathrm{~A}$ inspeção e a fiscalização de bebidas, nos seus aspectos bromatológicos e sanitários, são da competência do Sistema Único de Saúde, por intermédio de seus órgãos especificos.

(9) Entre as competências da Agência, exercidas também pelos Estados e Municípios, a Lei $n$. $9.782 / 99$ inclui as de estabelecer normas, propor, acompanhar e executar as politicas, as diretrizes e as açōes de vigiláncia sanitária; estabelecer normas e padrōes sobre limites de contaminantes, resíduos tóxicos, desinfetantes, metais pesados e outros que envolvam risco à saúde; autorizar o funcionamento de empresas de fabricação, distribuiçāo e importaçāo de produtos e serviços submetidos à vigilância sanitária. (art. $7^{0}$, incisos III, IV e VII). O controle de alimentos, águas e bebidas está previsto no art. 200, inciso VI, da Constituiçāo Federal.

(10) DALLARI, Sueli Gandolfi. "Os Estados brasileiros e o direito à saúde". São Paulo: Hucitec, 1995, D. 41

(11) DI PIETRO, Maria Sylvia Zanella. "Direito Administrativo", cit., p.188. 
tre órgãos administrativos (como Ministérios, Secretarias e suas subdivisões) e, dentro destes, entre seus agentes, pessoas físicas".

Posto que a competência, em matéria administrativa, decorra sempre da lei, ${ }^{(12)}$ nem sempre é tarefa simples definir os limites das atribuições das pessoas jurídicas, órgãos e servidores.

\section{QUESTÃO DE COMPETÊNCIA}

No dia 30 de julho de 1999, em Brasília-DF, vindo da Coordenação de Inspeção Vegetal do Ministério da Agricultura, um estranho ofício chegou às mãos do Dr. Cleber Ferreira dos Santos, Gerente-Geral da Divisão de Alimentos da ANVS. Assinada pelo coordenador substituto, Luiz Ferreira Filho, a comunicação epistolar questionava a emissão de um "Termo de Libera-: ção" emitido pela Diretoria de Vigilância Sanitária em Alimentos de Minas Gerais.

Para o servidor do Ministério da Agricultura, a ANVS devia explicar as circunstâncias em que se deu o ato administrativo praticado pela Secretaria de Estado da Saúde de Minas, porque, a seu juizo, competem ao Ministério da Agricultura "o registro, a padronização, a fiscalização e ainda a inspeção e a fiscalização da produção e do comércio de bebidas, em relação a seus aspectos tecnológicos". O texto do ofício enfatiza que, na opinião do coordenador substituto, "a liberação para a produção e a comercialização dos estabelecimentos fabricantes e engarrafadores de refrigerantes é da competência" do Ministério da Agricultura.

Voltando um pouco mais no tempo, resgatamos os fatos que geraram a infeliz tentativa de afirmação de competência. Tudo começou na noite de 4 de abril de 1999, por volta das 20h30m, no Municipio de Divinópolis-MG, quando três pessoas passaram mal depois de terem bebido o refrigerante "Guaraná Taça de Cristal", apresentando dores de cabeça, intensa dor de estômago, vômitos e diarréia.

O problema foi registrado pelo Setor de Fiscalização Sanitária da Prefeitura de Divinópolis, que colheu amostra do refrigerante e o enviou, para análise, ao órgão estadual. Conforme o relatório da Dra. Ligia Lindner Schreiner, Diretora de Vigilância Sanitária de Alimentos, o resultado condenatório da perícia realizada no produto motivou a interdição cautelar do "Guaraná Taça de Cristal", determinada no dia 7 de maio de 1999.

O Ministério da Agricultura foi informado dos fatos no dia 25 de maio de 1999. No dia seguinte, perante a direção estadual do Sistema Único de

(12) "A competência decorre sempre de lei, afastada que foi a atribuição do Poder Executivo nessa matéria, por força dos arts. $61, \S 1 \stackrel{1}{ }$ II, "e" e 84, VI, da Constituição e art. 25 de suas Disposiçōes Transitórias". DI PIETRO, Maria Sylvia Zanella. "Direito Administrativo", cit., p. 169. 
Saúde, o responsável legal pela empresa assumiu o compromisso de recoIher o "Guaraná Taça de Cristal" do comércio atacadista e varejista e de paralisar suas atividades produtivas até a apresentação e aprovação, pela autoridade sanitária, das "Boas Práticas de Produção".

Posteriormente, nos dias 14 de junho e 8 de julho de 1999, a Fundação Ezequiel Dias divulgou o resultado de análises microbianas realizadas em outras amostras do guaraná. Em ambos os laudos, o produto apresentou-se "em desacordo com os padrões vigentes" e, portanto, "impróprio para o consumo". O laudo indica que o processo de fabricação apresentava problemas de higiene indicados pelos bolores e leveduras em quantidade superior a permitida pela legislação sanitária. ${ }^{(13)}$

Relata a Dra. Schreiner que, no dia 21 de junho de 1999, "a equipe de vigilância sanitária avaliou as práticas de fabricação da empresa. Foram então constatadas condições favoráveis à contaminação e multiplicação microbiana (o produto permanece em tanques destampados por aproximadamente 15 horas à temperatura ambiente), tato já constatado pelas análises laboratoriais".

No relatório de inspeção, elaborado pela Diretora do Centro de Alimentos da Secretaria de Estado da Saúde de Minas Gerais, constam ainda as seguintes recomendações ao fabricante:

“É fundamental que a empresa:

- Desenvolva seus próprios procedimentos padronizados, descritos nas "Boas Práticas de Fabricação", elaborada tomando como base o seu próprio fluxograma de produção que deve encontrar-se à disposição de todos os empregados no momento da manipulação, a fim de evitar acidentes, como por exemplo superdosagem de aditivos. Os funcionários deverão ser treinados nas "Boas Práticas de Fabricação", bem como ter conhecimento dos malefícios à saúde causados pela ingestão excessiva dos componentes que eles manipulam e dos microorganismos ou suas toxinas;

- Mantenha registros de cada etapa do processo, principalmente naquelas consideradas pontos críticos, ou seja, pontos onde existe uma maior possibilidade de ocorrer contaminação ou multiplicação de microorganismos no alimento para permitir a rastreabilidade de eventuais erros no processamento;

- Trabalhe com fluxo de processamento contínuo, a fim de que não possibilite condições de tempo e temperatura para crescimento de microorganismos. Atualmente, o xarope fica exposto à temperatura ambiente, em recipiente destampado, de um dia para o outro. A tempera-

(13) Certificados de análise ns. 99/07/044 e 99/06/068, ambos da Divisāo de Bromatologia e Toxicologia da FUNDAÇÃO EZEQUIEL DIAS. 
tura, medida no momento em que o produto chegou ao tanque, foi de aproximadamente $50^{\circ} \mathrm{C}$, o que significa que o produto fica em temperatura ótima para o crescimento microbiano por aproximadamente 15 horas;

- Desenvolva mecanismos para que o alimento não fique exposto à contaminação do ambiente, como o que acontece nos tanques;

- Construa calçamento, plante grama, coloque brita, ou tome qualquer outra providência, na área externa, de forma a não permitir que a poeira seja suspensa no momento de trânsito de veículos ou pessoas, pois esta pode depositar-se no produto, contaminando-o;

- Organize o depósito de matéria-prima de forma que esta fique protegida de contaminação. Atualmente há produtos que entrarão em contato direto com os refrigerantes, como o carvão ativado, armazenado junto com material de limpeza, o que pode propiciar a contaminação química, por estes produtos, nos refrigerantes. Todos os produtos devem estar bem identificados. Deve haver programa de controle de fornecedores e de estoque;

- Construa pedilúvio nas áreas de acesso às salas de manipulação do alimento. Deve haver local de lavagem das botas, local para a higiene das mãos com sabonetes líquidos com sanizantes, papel-toalha descartável, ou secador de mãos de ar quente, sabão e desinfetante para as mãos, contíguo à sala de manipulação;

- Utilize apenas produtos de desinfecção permitidos para uso em indústrias de alimento, observando o binômio "concentração indicada pelo fabricante $X$ tempo de exposiçăo". Não é permitido o uso de compostos a base de formol, devido a sua alta periculosidade à saúde do manipulador e à possibilidade de contaminar o produto (refrigerante);

- Possua procedimentos de limpeza e desinfecção com a concentração correta dos desinfetantes;

- Os banheiros devem possuir sabonete líquido com sanitizantes e papéis toalha descartáveis e/ou secadores de mãos.

As recomendações do SUS, ora expressas, motivaram a questão de competência. $E$ os fatos relacionados a este caso são fortes para justificar providências visando a garantir a saúde e a segurança de todos. Está provado que a Vigilância Sanitária do Estado avaliou o processo tecnológico da indústria de refrigerantes e determinou as mudanças necessárias.

Como dissemos no início, outro ponto merecedor de atenção é a competência de Estados e Municípios. Com a criação da ANVS, algumas dúvidas surgiram a seu respeito. Ponto pacífico é que quanto aos aspectos tecnológicos que interessam à saúde e à segurança, o Estado e o Município podem exigir padrões mais rigorosos que as "regras gerais" expedidas pela União. 
É necessário desfazer as dúvidas definindo, com clareza, tanto as atribuições reservadas aos órgãos do SUS, quanto as de outros setores do Governo (Indústria e Comércio, Agricultura e Meio Ambiente, entre outros). No caso das bebidas, por exemplo, é preciso compreender o papel do Ministério da Agricultura a partir da interpretação da Lei n. 8.918/94.

Várias são as soluções possíveis. Pode-se até sustentar a derrogação, isto é, a revogação parcial do estatuto das bebidas pela Lei que organizou a ANVS ou interpretar seus dispositivos em harmonia com o sistema do direito positivo da saúde.

\section{EXAME DAS NORMAS APLICÁVEIS}

De acordo com o art. $2^{\circ}$ da Lei n. 8.918, de 14 de julho de 1994, invocado pelo funcionário do Ministério da Agricultura, o "registro, a padronização, e, ainda, a inspeção e a fiscalização da produção e do comércio de bebidas em relação aos seus aspectos tecnológicos, compete ao Ministério da Agricultura e do Abastecimento".

O mesmo diploma legal, em seu art. $3^{\circ}$, reza que "a inspeção e a fiscalização de bebidas, nos seus aspectos bromatológicos e sanitários, são da competência do SUS, por intermédio de seus órgãos específicos".

A interpretação reducente, expressa no ofício encaminhado pela coordenação de Inspeção Vegetal do Ministério da Agricultura, parte da premissa de que é possivel separar os "aspectos tecnológicos" dos "aspectos bromatológicos e sanitários". Trata-se de solução simplista que levaria à conclusão de que o Ministério da Agricultura seria o responsável único pelo processo industrial e o SUS teria poder sobre o produto; ou, como ainda chegam a insistir alguns, um órgão cuidaria da fiscalização na indústria, e o outro, no comércio varejista.

Tal interpretação não se harmoniza com os principios estabelecidos na Constituição Federal em relação à saúde como direito individual e social. Tampouco em relação à própria organização do SUS que prevê "descentralização político-administrativa, com direção única em cada esfera de governo".(14)

Como se sabe, a Lei n. 9.782/99 deu à ANVS o controle sanitário da produção e da comercialização de produtos e serviços submetidos à vigilância sanitária, inclusive "dos ambientes, dos processos, dos insumos e das tecnologias a eles relacionados" (art. 6\%). Pois bem, caso se entenda, com Luiz Ferreira Filho, que na Lei antiga todos os "aspectos tecnológicos" relacionados à produção de bebidas estariam subordinados ao Ministério da Agricultura, forçoso será afirmar que o art. $2^{\circ}$ da Lei $n .8 .918 / 94$ foi revogado pela Lei n. 9.782/99. 
Conforme dispõe a lei de introdução ao Código Civil, a lei nova revoga a anterior "quando seja com ela incompatível"(15). Reconhecida a incompatibilidade entre 0 art. $2^{\circ}$ da Lei n. 8.918/94 e o art. 6ำ da Lei $n .9 .782 / 99$, está revogado o texto antigo.

Por isso, tal solução não nos parece a melhor. Apesar da redação dada ao art. $2^{\circ}$ da Lei n. 8.918/94, não se sustenta a premissa de que todos os "aspectos tecnológicos" teriam sido outorgados ao Ministério da Agricultura. Não há como isolar a qualidade do produto em relação aos processos de produção empregados. Seria impossivel qualquer controle sobre os aspectos bromatológicos e sanitários das bebidas, pelo SUS, sem a análise dos processos tecnológicos empregados.

O caso concreto, que estamos examinando, é um bom exemplo desta afirmação. A Vigilância Sanitária apreendeu o "Guaraná Taça de Cristal" e o submeteu à pericia, constatando uma situação de risco à saúde. A melhor forma encontrada para a eliminação do perigo e a garantia da saúde do consumidor foi a revisão dos processos tecnológicos empregados pelo fabricante.

O SUS, conforme determinação contida na Constituição Federal, tem competência para controlar e fiscalizar procedimentos, produtos e substâncias de interesse à saúde; outrossim, para executar ações de vigilância sanitária e epidemiológica; para incrementar, em sua área de atuação, o desenvolvimento científico e tecnológico; e ainda fiscalizar e inspecionar alimentos, com o controle de seu teor nutricional, incluindo-se aí bebidas e águas para consumo humano. ${ }^{(16)}$

Assim, considerada a supremacia das normas constitucionais, o legislador ordinário jamais poderia ter tirado do SUS o controle sobre os aspectos tecnológicos da fabricação de bebidas que tenham impacto sobre a saúde individual e coletiva.

Estamos diante de uma norma Constitucional - o art. 200 - que determina a interpretação das regras específicas sobre bebidas, contidas na Lei n. 8.918/94 e das regras gerais sobre as açōes de vigilância sanitária previstas na Lei n. 8.080/90 e na Lei n. 9.782/99.

\section{SISTEMA NACIONAL DE VIGILÂNCIA SANITÁRIA}

É importante observar que a Lei n. 9.782/99 definiu o Sistema Nacional de Vigilância Sanitária, conforme previsto no art. 16, III, "d", da Lei n. $8.080 / 90$. Além disso, criou a agência reguladora, outorgando-lhe a função de coordenação.

(15) Art. $2^{\circ}, \S 1^{\circ}$ do Decreto-Lei n. 4.657, de 4 de setembro de 1942.

(16) Constituição Federal, art. 200, incisos I, II, V e VI. 
Seguindo o modelo adotado para a organização de outras agências reguladoras, como a ANEEL e a ANATEL, a opção do legislador foi pela criação de uma autarquia sob regime especial, vinculada ao Ministério da Saúde, com a finalidade institucional de promover a saúde da população por intermédio do controle sanitário da produção e da comercialização de produtos e serviços submetidos à vigilância sanitária. ${ }^{(17)}$ A ANVS goza de independência administrativa e financeira, contando ainda com a força legal da estabilidade de seus dirigentes.

Trata-se de um modelo importado da administração pública norte-americana, pelo qual funções de controle são outorgadas a órgãos administrativos independentes. Conforme autorizada doutrina, a criação das Agências no Brasil "está tirando do Poder Executivo" todas as atribuições que the são expressamente conferidas. ${ }^{(18)}$

A Agência, portanto, é o órgão executivo e coordenador do Sistema Nacional de Vigilância Sanitária. São atribuições suas:

— definir a política nacional de vigilância sanitária;

— definir o Sistema Nacional de Vigilância Sanitária;

- normatizar, controlar e fiscalizar produtos, substâncias e serviços de interesse à saúde;

- exercer a vigilância sanitária de portos, aeroportos e fronteiras, podendo essa atribuição ser supletivamente exercida pelos Estados, pelo Distrito Federal e pelos Municípios;

- acompanhar e coordenar as ações de vigilância sanitária nos Estados, Municípios e no Distrito Federal;

- prestar cooperação técnica e financeira aos Estados, ao Distrito Federal e aos Municípios;

- atuar em circunstâncias especiais de risco à saúde;

- manter sistema de informações de vigilância sanitária em cooperação com os Estados, o Distrito Federal e os Municípios.

Todas essas funções, com exceção da primeira (definição da política nacional de vigilância sanitária), são de competência da Agência Nacional de Vigilância, cujo extenso rol de atribuições está no art. $7^{\circ}$ da Lei n. $9.782 / 99$.

(17) Lei n. 9.782/99, arts. $3^{\circ}$ e $6^{\circ}$

(18) DI PIETRO, Maria Sylvia Zanella. "Direito Administrativo", cit., p. 391. 


\section{TECNOLOGIA E DIREITO}

É relevante, neste caso, o foco nos "aspectos tecnológicos". Cabe ao Estado promover e incentivar o desenvolvimento científico, a pesquisa e a capacitação tecnológicas ${ }^{(19)}$. Por outro lado, ciência e tecnologia devem estar sempre a serviço dos direitos fundamentais, "tendo em vista o interesse social e o desenvolvimento tecnológico e econômico do País". (20)

Podemos definir o fato tecnológico como sendo o "acontecimento resultante do ato tecnológico, ou seja, resultante da aplicação do conhecimento cientifico".(21)

O Estado intervém no controle das tecnologias, visando à proteção da saúde e da segurança. ${ }^{(22)}$ Conforme leciona a Professora Isabel Vaz, "o conhecimento tecnológico é reconhecidamente o meio mais eficaz de dominação dos mercados. Graças a esse poder é que os paises industrializados 'ditam as regras' não só nas relações econômicas internacionais, mas também em todos os planos das estratégias militares, de produção de insumos e matérias primas, indispensáveis à fabricação de equipamentos". (23)

É natural que o Ministério da Agricultura e do Abastecimento preocupe-se em apoiar e estimular as empresas que invistam em pesquisa, criação de tecnologia ou em formação e aperfeiçoamento de seus recursos humanos, conforme determina a Constituição Federal(24). Apoio efetivo à melhoria da qualidade e da produtividade é premissa obrigatória na Política Agrícola e também na Política de Abastecimento.

Função diferente é a executada pelo SUS na Vigilância Sanitária e na garantia da qualidade de alimentos, bebidas e águas. Nelas, o objetivo é reduzir o risco de doenças e outros agravos. ${ }^{(25)}$ A Agência Nacional de Vigilância Sanitária foi criada para executar o "conjunto de ações capaz de eliminar, diminuir ou prevenir riscos à saúde e de intervir nos problemas sanitári-

(19) Art. 218 da Constituição Federal.

(20) Art. $5^{\circ}$, inciso XXIX da Constituiçāo Federal.

(21) "Sua origem etimológica - discurso (logos) sobre as artes (techne) - possibilita a atribuição à tecnologia de um sentido amplo representado pela aplicação de um determinado conhecimento, em todos os momentos da açāo humana, ainda que em tempos remotos." AUGUSTO, Ana Maria Ferraz. "Ciência e tecnologia ern face do direito". Tese de doutoramento apresentada à Faculdade de Direito da Universidade Federal de Minas Gerais. $5^{2}$ ed., Belo Horizonte, 1985, p. 62.

(22) "O Estado deve assumir uma política de controle que, na ausência do risco tecnológico, seria desnecessária. Assim, visando ao interesse social, a intervenção do Estado se legitima, ainda que constituida por medidas de completo controle científico e tecnológico. Portanto, as restrições à livre pesquisa e à aplicaçāo de tecnologia na concretização de objetivos sociais constituem medidas de politica intervencionista que ampliam as condiçōes de luta pela sobrevivência." AUGUSTO Ana Maria Ferraz. "Ciência e tecnologia...", cit., p. 72.

(23) VAZ, Isabel. "Direito econômico da concorrência". Rio de Janeiro: Forense, 1992, p. 282.

(24) Art. 218, § 4ำ, da Constituição Federal.

(25) Art. 196, da Constituição Federal. 
os decorrentes do meio ambiente, da produção e circulação de bens e da prestação de serviços de interesse da saúde". ${ }^{(26)}$

Entre as ações da Vigilância Sanitária está o controle de bens de consumo que, direta ou indiretamente, se relacionam com a saúde, compreendidas aí todas as etapas e processos, da produção ao consumo (27). Assim, cabe ao SUS um "espaço tecnológico" diferente daquele que é objeto de cuidado por parte do Ministério da Agricultura.

Estudiosa da tecnologia em face do Direito, a Dra. Ana Maria Ferraz Augusto identificou, nas aplicações, diversos espaços tecnológicos, classificados por "setor de aplicação", "tipo de atividade" e "grau de nocividade". Verifica-se, portanto, que "há dezenas, senão centenas, de atividades tecnológicas bem caracterizadas, correspondendo às numerosas "células" do espaço tecnológico".

Por outro lado, sem perder de vista os princípios e os valores envolvidos, sublinha a doutrinadora que "cada 'espaço tecnológico' recebe do respectivo espaço científico uma carga ética específica. Assim, por exemplo, no espaço tecnológico médico, o compromisso ético originário é preservar a vida ou minimizar o sofrimento".(28)

\section{A RELAÇÃO DA AGÊNCIA COM ESTADOS E MUNICÍPIOS}

A Lei n. 9.782/99 define a competência exclusiva da União para algumas matérias. A leitura desse conjunto de funções ${ }^{(29)}$ exclusivas da ANVS mostra o grande poder que ela tem sobre fornecedores de produtos e serviços. A primeira é coordenar o Sistema Nacional de Vigilância Sanitária, atividade subordinada às diretrizes do Conselho Nacional de Saúde.

Em seguida, o legislador outorga a ela o poder de intervir na administração de fornecedores; de anuir com a importação e exportação dos produtos que envolvam risco à saúde pública; de proibir produtos em caso de risco à saúde; de cancelar autorização de funcionamento; de coordenar ações de vigilância sobre laboratórios; de estabelecer sistema de vigilância toxicológica e farmacológica, enfim, de promover a atualização periódica da farmacopéia.

(26) Art. $1^{2}$ da Lei n. 9.782, de 26 de janeiro de 1999 , c/c art. $6^{\circ}, \S f^{\circ}$, da Lel $n .8 .080$, de 19 de setembro de 1990.

(27) Art. $6^{9}, \S 1^{9}$, inciso I, da Lei n. 8.080, de 19 de setembro de 1990.

(28) "A título de exemplificação, indico como espaços tecnológicos específicos os relativos à tecnologia arquitetonica, tecnologia agricola, tecnologia de alimentos, tecnologia de edificaçōes, tecnologia educacional, tecnologia jurídica, tecnologia médica, tecnologia mineral, tecnologia meteorológica, tecnologia energética, etc." AUGUSTO, Ana Maria Ferraz. "Ciência e tecnologia...", cit., p. 39.

(29) Art. $7^{\circ}$ e seu $\S 1^{\circ}$, ambos da Lei n. 9.782, de 26 de janeiro de 1999. 
Os Estados e Municípios têm competência própria e, por delegação, podem receber outras atribuições. Entre as tarefas comuns destaca-se a possibilidade de estabelecer normas; de propor, acompanhar e executar as políticas, as diretrizes e as ações de vigilância sanitária. As regras estaduais em relação às federais serão necessariamente mais rígidas.

O próprio Município pode, igualmente, impor normas e padrões sanitários. Seu limite são os patamares mínimos fixados pelas legislações estadual e federal.

Em caso de violação da lei ou risco iminente à saúde, pode, também, como medida de vigilância sanitária, interditar locais de fabricação, controle, importação, armazenamento, distribuição e venda de produtos e de prestação de serviços relativos à saúde. ${ }^{(30)}$

Assim, dependendo da habilitação do Município ("Gestão Plena da Atenção Básica" ou "Gestão Plena do Sistema Municipal"(31)), e, ainda, de acordo com o próprio contrato que o liga ao SUS, o gestor terá sob sua responsabilidade uma relação de estabelecimentos, produtos e serviços sujeitos à inspeção. Pode o Município exigir níveis de segurança e salubridade mais rigorosos que o Estado e a União, exercendo controle sobre os processos tecnológicos envolvidos em cada atividade produtiva.

Com o avanço do processo de descentralização, é natural que os Municipios assumam a execução das ações de vigilância sanitária sob a coordenação da Agência federal e dos órgãos estaduais e regionais equivalentes. Tal controle, voltado à garantia da qualidade e da segurança dos produtos e serviços, abrange os ambientes, os processos, os insumos e as tecnologias a eles relacionados.

A delegação de competências, prevista no $\S 1^{\circ}$ do art. $7^{\circ}$ da Lei que criou a Agência Nacional de Vigilância Sanitária, recepciona os complexos de obrigações já estabelecidos nos diversos contratos de gestão. Assim, as obrigações e direitos da Uniāo relativos à vigilância sanitária ficam transferidos para a ANVS, mantendo-se vigentes os atos administrativos de delegação de competência, quando necessários.

\section{CONCLUSÃO}

O dever de "cuidar da saúde" impõe ao Estado a obrigação de controlar as tecnologias envolvidas na produção, distribuição e consumo de diver-

(30) Art. $7^{9}$, inciso XVI, da Lei n. 9.782, de 26 de janeiro de 1999.

(31) De acordo com a NOB-96, as açōes de vigilância sanitária classificam-se em ações básicas (de responsabilidade tipicamente municipal), ações de média complexidade e açōes de alta complexidade. O elenco de procedimentos incluidos em cada categoria deve ser definido em negociação na comissão tripartite, por gestores da Uniāo, dos Estados e dos Municípios (Norma Operacional Básica do SUS. NOB-SUS 01/96, publicada no Diário Oficial da União de 6 de novembro de 1996). 
sos produtos e serviços. Nos vários "espaços tecnológicos", atua o SUS, na função de vigilância à saúde, cuidando da segurança individual e coletiva; atuam também outros órgãos, da agricultura, indústria, meio ambiente, que avaliam as tecnologias sob outra perspectiva.

À União cabe estabelecer normas gerais. Os patamares mínimos são aqueles fixados nos regulamentos federais que contêm especificações para - produto e para os processos tecnológicos. Os Estados e os Municípios, suplementarmente, podem estabelecer normas até mais rígidas. ${ }^{(32)}$ Podem também avaliar os aspectos tecnológicos de qualquer atividade desenvolvida em seu território.

Assim, tanto em relação a alimentos quanto a bebidas, águas e outros produtos sujeitos à vigilância sanitária, o Estado e o Município têm o dever de controlar as tecnologias empregadas e de monitorar os riscos através dos pontos críticos de controle.

\section{REFERÊNCIAS BIBLIOGRÁFICAS}

AUGUSTO, Ana Maria Ferraz. "Ciência e tecnologia em face do direito". Tese de doutoramento apresentada à Faculdade de Direito da Universidade Federal de Minas Gerais. 5ª ed., Belo Horizonte, 1985.

DALLARI, Sueli Gandolfi. "Os Estados brasileiros e o direito à saúde". São Paulo: Hucitec, 1995.

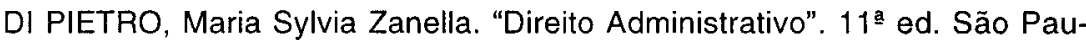
lo: Atlas, 1999.

FONSECA, João Bosco Leopoldino da. "Direito Econômico". Rio de Janeiro: Forense, 1995.

FUNDAÇÃO EZEQUIEL DIAS. Certificados de análise ns. 99/07/044 e 99/ 06/068, ambos da Divisão de Bromatologia e Toxicologia da Fundação Ezequiel Dias.

SANTOS, Jair Lício Ferreira e WESTPHAL, Márcia Faria. "Práticas emergentes de um novo paradigma da saúde: o papel da universidade". In Estudos Avançados, São Paulo: Universidade de São Paulo, v. 35, 1999.

URUGUAI, Paulino José Soares de Souza, Visconde de. Ensaio sobre o Direito Administrativo. Brasília: Ministério da Justiça, 1997.

VAZ, Isabel. "Direito econômico da concorrência". Rio de Janeiro: Forense, 1992.

(32) Nas cidades com temperaturas e umidade elevadas, os riscos à saúde, em face de condições locais, podem exigir a definição de itens e niveis de controle mais rigidos em relação a insumos, processos industriais, produtos e serviços. 